\title{
THE HISTORICAL DEVELOPMENT OF THE STUDY OF BROCA'S APHASIA
}

\author{
Yoke Lian Lau ${ }^{1,2}$, Chek Kim Loi ${ }^{3}$, Mohd Nor Azan bin Abdullah ${ }^{2}$ \\ Correspondence: yokelian@ums.edu.my \\ ${ }^{1}$ Department of Applied Linguistics, Tsinghua University, 100084, Beijing, China \\ ${ }^{2}$ Centre for the Promotion of Knowledge and Language Learning, 88400, Universiti Malaysia Sabah, Kota Kinabalu, Sabah, Malaysia \\ ${ }^{3}$ Centre for the Promotion of Knowledge and Language Learning, 87000 Labuan, Wilayah Persekutuan Labuan, Universiti Malaysia \\ Sabah, Malaysia
}

\begin{abstract}
Article History:
Received: December 23, 2020

Accepted: May 28, 2021

Published: July 1, 2021

Cite this as:

Lau YK, Loi CK, Abdullah MNA.

The historical development of the study of broca's aphasia. Malang Neurology Journal; 2021.7: 125-

\section{ABSTRACT}

Broca's aphasia is a type of aphasia named after the French surgeon Broca. Broca's aphasic patients experienced difficulty in speaking, but they could understand both spoken and written language. There were three essential patients in the historical development of the study of Broca's aphasia. Louis Victor Leborgne (1809-1861) was also known as Monsieur Leborgne or 'Tan' as he could only utter the syllable 'Tan' throughout his 21 years of illness. The second patient was called Lazare Lelong. His language ability was slightly better than Leborgne. He could utter simple syllables, such as oui (yes), non (no), and this (trois or three). The third patient was Gage, a railway company worker. Broca studied similar cases in the following years and planned a brain function localization theory.
\end{abstract} 12.

http://dx.doi.org/10.21776/ub.mnj .2021.007.02.8

Keywords: Broca's aphasia, historical, Lelong, Leborgne, Phineas Gage

\section{Introduction}

Broca's aphasia is a type of aphasia named after the French surgeon Paul Broca. The primary manifestation is difficulty in speaking, but the ability to understand spoken and written language is relatively standard, also called 'expressive aphasia'. ${ }^{1}$ Broca's area is at the motor cortex's mouth in the frontal area of the brain. The lips and vocal cords represent the front part of the site. When the central part of the posterior part of the superior hemisphere of motor language is damaged, this will also affect speech pronunciation. Therefore, the neural pathways controlled by language movement cannot operate normally, so Broca's aphasia is also called 'motor aphasia/anandia'., ${ }^{2,3,4,5,6,7}$

Some patients with Broca's aphasia have no sentence rehearsal disorder. In other words, their retelling ability is intact. Their oral comprehension is good, but there could be severe dyspraxia, anomia, and writing defects $8,9,10,11,12$. There is right hemiplegia in most patients, as the lesion is mainly in the anterior or upper part of the dominant hemisphere - mainly in the middle or anterior portion of the inferior frontal region - it is also known as cortical motor aphasia. ${ }^{9,11,12}$

There are various titles for Broca's aphasia, such as expressive aphasia, motor aphasia, cortical motor aphasia, and 'coding' aphasia. Although the names are different, they all emphasize the motor and expression disorder of Broca's aphasia. When patients speak, it is often difficult for them to find words, causing long pauses and communication to slow down. Since the sentences produced contain simple nouns, verbs, and adjectives, there is a lack of grammar and appropriate ending changes. This type of language is also known as telegraph language or agrammatism. The patient's words will also lack normal language rhythm and tone, which is extremely unnatural. In severe cases, patients can only repeat one or two words when describing something due to difficulty articulating. It is difficult for them to communicate with others in a normal language. ${ }^{2.34 .8,9,10,11,12}$

\section{From Gall to Broca}

The German anatomist and psychologist Franz Joseph Gall (1758-1828) was the first to link brain function to specific brain locations. He marked individual attributes based on each skull's structure, such as advocacy, brutality, loyalty, and so on. He believed that the head's design changed with the development of human beings. ${ }^{8,13,14}$ For Gall, the place where the skull rises represented excellent human qualities, whereas the place where there is a depression in the head represented certain human defects. The study of skulls became the standard for assessing a person's virtues, leading to cortical positioning, which is notorious in the medical profession. ${ }^{8}$ As the first person specializing in the brain positioning theory, Gall left some valuable ideas. For example, he distinguished six different memories: verbal, grammatical, the relation of numbers, locality, colors, and tonal harmony. This later laid the foundation for Bouillaud's theory of language lateralization.,14

French doctor Jean-Baptiste Bouillaud (1796-1875) proposed in 1825 the idea that language function is in the brain's front. ${ }^{8,15,16} \mathrm{He}$ believed that all the roots of language pathology come from the frontal lobe of the brain. His son- 
in-law and student Ernest Auburtin (1825-1893) also strongly supported his theory. He claimed that although the frontal lobe is damaged, and the lesion is beyond the frontal lobe, it is impossible to directly prove that the frontal lobe is damaged and language ability is lost. Broca himself was also a supporter of the brain function orientation theory. Bouillaud's idea inspired his focus on the frontal lobe of the brain. Broca's subsequent success was the implementation of Bouillaud's doctrine. ${ }^{4,8,15,16}$

The debate between scholars engaged in brain function localization and whole-brain theory became very intense in the middle of the nineteenth century. At the Parisian Anthropological Society meeting on 4 April 1861, scholars from both schools of thought engaged in a discussion. During the conference, embryologist Louis Pierre Gratiolet (1815-1865) said that a larger brain shows higher intelligence also fuelled controversy among scholars ${ }^{11,12,17}$. Auburtin's point of view at the meeting inspired Broca, which later led to Broca inviting him to take part in a consultation session involving a patient who experienced a loss in language ability and paralysis symptoms on the right side of the body. ${ }^{8,15}$

\section{Three Important Patients}

There are three essential patients in the historical development of the study of Broca's aphasia. The patient called Louis Victor Leborgne (1809-1861) was also known as Monsieur Leborgne or 'Tan' because he only uttered the syllable 'tan' in his 21 years illness. ${ }^{2,4,5,6,7,8,9,17,18,19,20} \mathrm{He}$ was born in a small village in France on 21 July 1809. His father was a primary school teacher, and he had five brothers and sisters. Leborgne's physical condition was poor, as he had epilepsy from a young age. However, he worked until he turned 30, as his language ability became a barrier. Although he could not talk, his intelligence level was normal as he could understand what other people said. The only syllable he could utter was 'tan,' but he could also respond to 'tan' in various tones and gestures. ${ }^{5,6,14,18}$ His family thought it was only a temporary condition and did not take him to the hospital for treatment. Ten years later, he became hemiplegic on the right side. Another four years later, his hemiplegia gradually became severe. After seven years, on 11 April 1861, he was transferred to the department of Bicêtre Hospital surgery at which Broca was working. He was placed under Broca's care. ${ }^{2}$

Leborgne's case is defined as a significant example of Broca's aphasia patient. Some latest research argues that Leborgne might have other cognitive problems due to his brain-injured involvement such a big portion ${ }^{4}$. And his situation becomes worse when sending to Broca's hand, as his family sent him to the hospital when he was $30 .{ }^{17,18,19,20}$

The relationship between severity and the family's decisionmaking level to the departure interval when a patient has a stroke can go to the emergency department as soon as possible could be one reason the situation worsens. ${ }^{21}$

Leborgne was 52 years old. Broca realized he was a case in which Bouillaud's brain function localization theory could be confirmed, so Auburtin was invited to participate in the consultation. Six days later, Leborgne died. Broca dissected his brain and found that there was a large lesion on the inferior frontal lobe. The second frontal convolution of the left cerebral hemisphere was damaged, and the injury was most profound. This area was later named Broca's area, and aphasia caused by damage to the $\mathrm{x}$-domain of this area was later named Broca's aphasia. $4,5,615,16,17,18,19,20$

Broca believed that this case confirmed Bouillaud's view that language functions were at the forefront of the brain. Although he knew that a single case was not sufficiently convincing, he published his findings at the Paris Anthropology Conference on 18 April $1861 .^{2}$ His views attracted little attention. Four months later, Broca submitted a neurological, anatomical report on Leborgne and published it in the Anthropological Society Journal. The report officially proposed the existence of the loss of the frontal lobe and language ability. ${ }^{2}$

In the same year, Broca submitted the autopsy report of another patient ${ }^{2}$. Like Leborgne, this patient had lost his language ability. After dissection, it was found that his posterior inferior frontal lobe was damaged, and it closely resembled Leborgne's brain damage. The second patient, called Lazare Lelong, was an 84-year-old worker sent to the hospital due to dementia. His language ability was slightly better than Leborgne's as he could utter five simple syllables, namely: oui (yes), non (no), tois (trois, or three), toujours (always), and Lelo (when he tried to speak his name). ${ }^{2,4,20}$

Whenever he said 'tois,' somebody's language was accompanied, especially the swinging of his fingers to correct linguistic errors. For example, when asked how many children he had, he replied with 'tois' but showed four fingers. When asked if he had any daughters, he said 'tois' but showed three fingers. Lelong died 12 years after he had a fall. Broca dissected his brain and discovered that his lesion was like Leborgne. ${ }^{4}$

In the next few years, Broca collected similar cases. He published the anatomical report of the case. The more accurate the brain function localization theory, the more he realized the human left hemisphere was more likely to be the functional language area than the right hemisphere. In 1863, Broca reported eight cases of language output disorders. None of the patients in the eight cases could speak, and their autopsy reports showed that damage to the frontal lobe of the left hemisphere had led to the loss of language ability. Another case involved damage to the frontal lobe of the right hemisphere. In 1865, Broca announced his research conclusion-'humans speak with the left hemisphere' ('Nous parlons avec l'hemisphere gauche' 13 [Herron, 2012, p. 19]). ${ }^{2}$

The words 'tois' and 'trois' in French are pronounced virtually the same but have different meanings, origins, and spellings. As a native speaker, Broca could identify the word 'tois' by the patient's gestures, 'trois,' and quickly recognized that the patient was trying to say the number' three.' However, it is difficult for non-native speakers to identify 'tois' as 'trois,' especially when the patient showed an incorrect number of fingers. In French, all three words (tois/twa/no meaning, Toi /twa/ pronoun 'You' informal, and Toit /twa/ roof) are pronounced similarly. However, it does not mean that it is the number 'three. ${ }^{4,18,19}$, 
Table 1. Lazare Lelong speaks five simple syllables

\begin{tabular}{|c|c|c|}
\hline Syllable & Meaning & Other \\
\hline oui & yes & - \\
\hline non & no & - \\
\hline $\begin{array}{l}\text { Tois /twa } \\
\text { (Trois/trwa) }\end{array}$ & $\begin{array}{l}\text { No meaning } \\
\text { Three }\end{array}$ & $\begin{array}{l}\text { Using gestures } \\
\text { and the patient's } \\
\text { words, Broca } \\
\text { could identify that } \\
\text { the word 'tois' } \\
\text { referred to the } \\
\text { number trois } \\
\text { (three). }\end{array}$ \\
\hline toujours & always & \\
\hline Lelo & $\begin{array}{l}\text { When he spoke his } \\
\text { name }\end{array}$ & - \\
\hline
\end{tabular}

Besides the study of Gall and his followers, an incident in the United States further reinforced brain function localization.

Phineas Gage (1823-1869) was originally a railway company worker. On 13 September 1849, at 4:30 pm, he and his workmates worked for the Rutland and Burlington Railway Company. Gage placed blasting powder in a deep hole and packing the powder with a tamping iron rod. The steel rod weighed 13.25 pounds, was 3 feet 7 inches long, and had a diameter of 1.25 inches. The rod was tapered at one end. During the subsequent accident, the iron rod was driven entirely through Gage's head, but miraculously he survived. Nevertheless, he lost his language ability and observed changes in his temperament. ${ }^{14,15,22}$

\section{The Intellectual Property Dispute in The Left-Brain Control Language Theory}

In 1836, Marc Dax (1770-1837), a rural doctor from the south of France, published more than 40 aphasic brain damage reports of his discoveries at regional doctors' conferences. Medical reports of aphasia often accompany left brain injury cases. His reports pointed out that among language disorder patients who gained aphasia due to brain damage caused by accident and stroke, the number of patients with paralysis on the right side of the body was far more than that of the body's left side. The left hemisphere of the brain controls the movement of the right side of the body, and language output disorders accompany the paralysis of the right side of the body. His findings were reported 25 years earlier than Broca's. ${ }^{15,23,24,25,26}$

Marc Dax's son, Gustave Dax (1815-1893), submitted his article to Academie de Medenine in Paris in 1863, but it was rejected. He later offered the paper to another publication named 'Gazette hebdomadaire de Medicine et de chirurgie'. The report 'Lesions of the left half of the encephalon coinciding with the forgetting of signs of thought' (original title: Lesions de la moitie gauche de L'encephale coincident avec l'oublie des signes de la pensee) was published in 1865 . $^{8,23,24,25,26}$

Four years after Broca presented his report, Gustave Dax appealed to the Paris medical community, advocating that left hemisphere dominance for language should rightfully be his father's intellectual property. The attempt was unsuccessful because his father's report was not published in time, even though it was published two weeks earlier than Broca's report in a small publication in $1865^{3,7}$. Unfortunately, the journals were not considered authoritative and representative. Cubelli and Montagna $(1994)^{3}$ thought Marc Dax's contribution was also significant and that the relevant theory should be renamed 'The Theory of Dax-Broca'. ${ }^{3}$

\section{The Contributions and Disadvantages of Broca's Theory}

Broca is considered a pioneer and significant contributor's well-deserved status in the neuro-basic study of language. One of his main achievements was that he discovered that the left hemisphere is the dominant hemisphere of language and that the right hemisphere is the minor hemisphere ${ }^{7}$. Of course, this conclusion is only statistically significant as the right hemisphere dominates some language functions. Broca's contributions are discovering the inferior frontal gyrus, also known as Broca's area, the language-generating area. If a patient cannot pronounce words and speak, it is probably due to the dysfunction of the inferior frontal gyrus. $^{2}$

Broca's theory of 'humans speaking with the left hemisphere' has dominated medical and scientific thinking for decades. He believed that language barriers are obstacles to performing everyday tasks such as speaking, understanding, reading, and writing. While this approach focuses on daily tasks based on language communication, allowing researchers to explore how the brain is related to language function also has drawbacks. For decades, it has hindered the investigation of the organizational part of physiological linguistic tasks that negatively impact aphasia, neurolinguistics, and treatment methods ${ }^{8,28,29}$.

Decades ago, to judge a Broca's patient was more quickly, and the focused factors were more concentrated. However, families play a crucial role in helping Broca's patients; families due to the caregiver's lack of knowledge could be caused to patients' delay to deliver to gets their consultant. ${ }^{27}$

\section{Conclusion}

The development of Broca's aphasia, if tested today by using the advanced method, might occur some debate, but the contribution of Broca's to the aphasia field could not be questioned. The effort of Gustave Dax to call for the recognition of his father's discovery should be paying more attention and giving credit; Gustave Dax should be considered a person to fight for intellectual rights in this field and not just a messenger boy.

\section{Acknowledgment}

This work was supported by The National Social Science Fund of China (14BYY065).

\section{Conflict of Interest}

The authors declare that there is no conflict of interest. 


\section{References}

1. Mesulam M-M. Primary progressive aphasia. Annals of Neurology; 2001. 49(4):425-32.

DOI: 10.1002/ana.91

2. Berker EA. Translation of Broca's 1865 Report. Archives of Neurology; 1986. 43(10):1065-72. DOI: 10.1001/archneur.1986.00520100069017

3. Cubelli R, Montagna CG. A reappraisal of the controversy of Dax and Broca. Journal of the History of the Neurosciences; 1994. 3(4):215-26.

DOI: 10.1080/09647049409525614

4. Dronkers NF, Plaisant O, Iba-Zizen MT, Cabanis EA. Paul Broca's historic cases: High-resolution MR imaging of the brains of Leborgne and Lelong. Brain; 2007. 130(5):1432-41. DOI:10.1093/brain/awm042

5. Finger S. Paul Broca (1824-1880). Journal of Neurology; 2004;251(6). DOI: 10.1007/s00415-0040456-6

6. Freemon FR. Paul Broca: Founder of French anthropology, explorer of the brain. JAMA: The Journal of the American Medical Association; 1993. 270(12): 1480 .

DOI: 10.1001/jama.1993.03510120104043

7. Buckingham HW. The Marc Dax (1770-1837)/Paul Broca (1824-1880) controversy over priority in science: Left hemisphere specificity for seat of articulate language and for lesions that cause aphemia. Clinical Linguistics \&amp; Phonetics; 2006. 20(78):613-9. DOI: 10.1080/02699200500266703

8. Lee DA. Paul Broca and the history of aphasia: Roland P. Mackay Award Essay, 1980. Neurology; 1981. 31(5):600-02. DOI: 10.1212/wnl.31.5.600

9. Stone JL. Paul Broca and the first craniotomy based on cerebral localization. Journal of Neurosurgery; 1991. 75(1):154-9. DOI: 10.3171/jns.1991.75.1.0154

10. Nishitani N, Schürmann M, Amunts K, Hari R. Broca's Region: From action to language. Physiology. 2005;20(1):60-9.

DOI: $10.1152 /$ physiol.00043.2004

11. York GK. Localization of language function in the twentieth century. Journal of the History of the Neurosciences; 2009. 18(3):283-90.

DOI: $10.1080 / 09647040802025979$

12. Pearce JMS. Broca's aphasiacs. European Neurology; 2009. 61(3):183-9. DOI: 10.1159/000189272

13. Eling $\mathrm{P}$, Finger S. Franz Joseph Gall on the Cerebellum as the Organ for the Reproductive Drive. Frontiers in Neuroanatomy; 2019. 13. DOI: 10.3389/fnana.2019.00040

14. Brown J. Phrenological studies of aphasia before Broca: Broca's aphasia or Gall's aphasia? Brain and Language; 1992;43(3):475-86. DOI: doi.org/10.1016/0093-934X(92)90113-S

15. Stookey B. Jean-Baptiste Bouillaud and Ernest Auburtin. JAMA; 1963. 184(13): 1024. DOI: 10.1001/jama.1963.73700260007011

16. Luzzatti C, Whitaker H. Jean-Baptiste bouillaud, claude-françois lallemand, and the role of the frontal lobe. Archives of Neurology; 2001. 58(7):1157. DOI: 10.1001/archneur.58.7.1157
17. Pearce JMS. Louis Pierre Gratiolet (1815-1865): The cerebral lobes and fissures. European Neurology; 2006. 56(4):262-4. DOI: 10.1159/000096679

18. Signoret J-L, Castaigne P, Lhermitte F, Abelanet R, Lavorel P. Rediscovery of Leborgne's brain: Anatomical description with CT scan. Brain and Language; 1984. 22(2):303-19. DOI:10.1016/0093934X(84)90096-8

19. Code C. Did Leborgne have one or two speech automatisms? Journal of the History of the Neurosciences; 2013. 22(3):319-20. DOI: $10.1080 / 0964704 X .2013 .776296$

20. Domanski CW. Mysterious "Monsieur Leborgne": The mystery of the famous patient in the history of neuropsychology is explained. Journal of the History of the Neurosciences; 2013. 22(1):47-52.

DOI: 10.1080/0964704X.2012.667528

21. Rahmawan FA, Yueniwati Y, Suharsono T. Perception of severity level and decision making of family correlation toward departing interval of patient suffering ischemic stroke. MNJ (Malang Neurology Journal); $2020 . \quad 6(2), \quad 63-68$. DOI:10.21776/ub.mnj.2020.006.02.3

22. Macmillan, M. A wonderful journey through skull and brains: The travels of MR. GAGE'S tamping iron. Brain and Cognition; 1986. 5(1):67-107. DOI:10.1016/0278-2626(86)90062-X

23. Manning L, Thomas-Antérion C. Marc Dax and the discovery of the lateralisation of language in the left cerebral hemisphere. Revue Neurologique; 2011. 167(12):868-72. DOI: 10.1016/j.neurol.2010.10.017

24. Finger S, Roe D. Gustave Dax and the early history of cerebral dominance. Archives of Neurology; 1996. 53(8):806-13.

DOI: 10.1001/archneur.1996.00550080132021

25. Finger S, Roe D. Does Gustave Dax deserve to be forgotten? The temporal lobe theory and other contributions of an overlooked figure in the history of language and cerebral dominance. Brain and Language; 1999. 69(1):16-30.

DOI: $10.1006 /$ brln.1999.2040

26. Roe D, Finger S. Gustave Dax and his fight for recognition: An overlooked chapter in the early history of cerebral dominance*. Journal of the History of the Neurosciences; 1996. 5(3):228-40. DOI: $10.1080 / 09647049609525672$

27. Pariama AM, Ranimpi YY, Setiawan A. Subjective well-being and healthy behavior of elderly with dementia alzheimer's (A Phenomenological study). MNJ (Malang Neurology Journal); 2020. 6(2), 82-87. DOI: 10.21776/ub.mnj.2020.006.02.7

28. Lazar RM, Mohr JP. Revisiting the contributions of Paul Broca to the study of aphasia. Neuropsychology Review; 2011;21(3):236-9. DOI: 10.1007/s11065011-9176-8

29. Clower WT, Finger S. Discovering trepanation: The contribution of Paul Broca. Neurosurgery; 2001. 49(6):1417-26. DOI: 10.1097/00006123-20011200000021 